\title{
Nicotine control: E-cigarettes, smoking and addiction
}

\author{
Kirsten Bell, Helen Keane
}

NOTICE: this is the accepted version of a work that was accepted for publication in International Journal of Drug Policy. A definitive version was subsequently published in International Journal of Drug Policy, 2012, volume 23, issue 3, pages 242-247. DOI: http://dx.doi.org/10.1016/j.drugpo.2008.06.002

\begin{abstract}
Over the past year or so, electronic cigarettes, more commonly known as 'e-cigarettes', have achieved widespread visibility and growing popularity. These products, which deliver nicotine via an inhaled mist, have caused no small amount of controversy in public health circles, and their rise has been accompanied by energetic debate about their potential harms and benefits. Interspersed with an analysis of current media coverage on e-cigarettes and the response of mainstream tobacco control and public health to these devices, this article examines the emergence of nicotine as both as an 'addiction' and a treatment for addiction. We argue that by delivering nicotine in way that resembles the visual spectacle and bodily pleasures of smoking, but without the harms of combustible tobacco, e-cigarettes highlight the complex status of nicotine as both a poison and remedy in contemporary public health and tobacco control. In consequence, they jeopardize the carefully drawn distinctions between 'good' and bad' forms of nicotine.
\end{abstract}

\section{Introduction}

In the recent film The Tourist we first meet Johnny Depp's character, Frank, through the eyes of Elise (Angelina Jolie), as he sits in a train carriage reading a spy novel and puffing on what appears to be a cigarette. For many viewers of the film, this was their first glimpse of an electronic cigarette, or 'e-cigarette', a device, as Frank quickly informs Elise, that is "not a real cigarette. It's electronic. It delivers the same amount of nicotine but the smoke is water vapour". 1

Invented by a Chinese pharmacist named Hon Lik in 2003, the e-cigarette was launched by the Chinese electronics company Ruyan Technology three years later, and received its first international patent in 2007 (Wikipedia, 2011). E-cigarettes now have a dedicated following amongst a small but growing number of users known as "vapers". The appearance of the ecigarette in The Tourist marks a new visibility for the product - a visibility that has been accompanied by energetic debate about its potential harms and benefits.

Opinion on e-cigarettes has quickly polarised. For harm reduction organisations such as the Consumer Advocates for Smoke-Free Alternatives Association (CASAA) and the Australian Tobacco Alternatives Consumer Association (ATACA), along with a growing number of smokers themselves, e-cigarettes have been embraced as a healthier alternative to smoking cigarettes. Advocates also highlight their ability to provide some of the non-nicotine rewards of smoking, such as sensory stimulation, and mouth and throat feel. A few health agencies have followed suit and deemed e-cigarettes a "far safer" alternative to smoking (e.g. NZ Ministry of 
Health, 2011). However, most mainstream public health organisations have condemned these products, some banning sales altogether (e.g. Health Canada, 2009) and others characterising them as "poison" and warning the public not to use them (e.g. Queensland Health, 2011). For these organisations, e-cigarettes represent the latest incarnation of the tobacco menace: an untested product with the potential to enslave ever-greater numbers of people (especially impressionable youth) to a dangerous addiction.

Despite the fact that e-cigarettes contain no tobacco (and in some cases, no nicotine), the World Health Organization has classified them as a tobacco product much along the lines of smokeless tobacco (WHO, 2011: 40). Initially, the US Food and Drug Administration (FDA) attempted to assert jurisdiction over e-cigarettes as a drug device; however, the US Court of Appeals overturned their decision in December of 2010. Therefore, the FDA is currently attempting to obtain jurisdiction over e-cigarettes as a tobacco product (Boen, 2011; Sullum, 2011). The European Union (EU) is similarly grappling with whether to regulate e-cigarettes as medical or tobacco products (Irish Central, 2011). The FDA and EU's difficulty in classifying e-cigarettes reflects the ambiguous middle ground these products occupy between medicinal forms of nicotine (i.e. nicotine replacement therapy, or 'NRT') and smokeless tobacco.

This paper examines the reception of e-cigarettes and seeks to understand why mainstream public health agencies and tobacco control advocates have been so quick to condemn these products. Our analysis involves a critical reading of a range of texts, including media reports, policy briefs from health agencies and harm reduction organisations, vaper websites and blogs, journal articles and commentaries. Bill Godshall's Tobacco Harm Reduction Update listserv, which provides a weekly compilation of media coverage and policy developments regarding ecigarettes (amongst other topics), ${ }^{2}$ provided a key resource in identifying literature, supplemented by searches of Google Scholar. Although we have tried to capture the tenor of current debates about e-cigarettes, we make no claims to the comprehensiveness of our examination - an impossibility given the topicality of this issue and the speed with which new developments are occurring. Moreover, we have not restricted ourselves to literature on ecigarettes, but have sought to locate our examination within a broader historical and cultural context, recognising that current responses to e-cigarettes are inextricably bound up with older debates about nicotine and the concept of addiction.

This article begins with an historical overview of tobacco and nicotine's distinctive relationship with the concept of addiction, and the rise of medicinal nicotine as a treatment for tobacco dependence and its perceived relationship to other forms of nicotine such as smokeless tobacco. Following this contextualisation, the second half of the paper focuses on the reception of ecigarettes, which we suggest cannot be reduced exclusively to the untested nature of these products. Rather, much of the hostility e-cigarettes have engendered, we argue, stems from the instability these products crystallise in the ideological distinctions drawn between nicotine as either a 'poison' or a 'cure'.

\section{Nicotine as an addictive drug}

As is now well established, although nicotine is the addictive ingredient in tobacco, the harms associated with tobacco smoking stem primarily from the carcinogens in cigarette smoke (tar, carbon monoxide, etc.) rather than nicotine itself. The long-term effects of nicotine have not 
been well studied, and both its potential therapeutic benefits and its carcinogenic properties remain contested. Moreover, although nicotine addiction has become central to explaining the resilience of smoking among some sections of the population, the concept of tobacco 'addiction' is of relatively recent vintage and, as we go on to show, manifests important underlying ambiguities.

Nicotine was first isolated and named in 1828 and by 1889 researchers had begun studying its effects on the nervous system; by the turn of the twentieth century its role in incentivising smokers to smoke was taken for granted (Sullum, 1998). In 1942, based on the hypothesis that "Smoking tobacco is essentially a means of administering nicotine, just as smoking opium is a means of administering morphine", Johnston (1942, p. 742) found that injections of nicotine did reduce the urge to light up in smokers. However, although Johnston characterised the desire for nicotine as an "addiction", the comparison with opium has clear limits. Unlike opiate use, the psychoactive effects of nicotine are subtle and do not interfere with mental performance or handeye coordination. In fact, they have been shown to improve concentration and the performance of some cognitive tasks. Consequently, in contrast to other recreational drugs such as alcohol, heroin or cocaine, tobacco's main advantage is its compatibility with the requirements of everyday life (Keane, 2002).

Despite the pharmacological evidence of nicotine's addictiveness and the effects of smoking on health, smoking is incongruent with dominant models of addiction, both medical and popular. As Robin Room (2003) has argued, one of the cultural functions of the concept of addiction is to provide a causal explanation for bad behaviour. Addiction is seen as a kind of possession, in which a powerful drug is able to produce behaviour that would not otherwise occur. But while smokers may be dependent on a drug to function, their lives generally appear ordinary, orderly and productive. Because cigarettes do not produce intoxication and remain legal and relatively easy to access, smokers do not fit the stereotype of the out-of-control junkie governed by an unmanageable desire, at least until they try to quit (Keane, 2002). Indeed, in accounts of quitting, it is the effects of giving up, at least in the short term, that render the smoker physically debilitated, psychologically distressed and prone to erratic and uncharacteristic behaviour.

Because of these anomalies, it was only relatively recently that tobacco use was officially identified as an 'addiction'. As Berridge (1998) has shown, in the British context, tobacco was historically seen to be associated with dependence rather than addiction per se. Tobacco therefore emerged as a policy focus through chest medicine and epidemiology rather than psychiatry. The importation of tobacco into the addiction frame only took place in the 1990s, primarily due to the influence of US models (Berridge, 1998, p. 157). Although tobacco was drawn into the addiction realm earlier in the USA, the 1964 Surgeon General's Report characterised "the tobacco habit" as a "habituation" related primarily to social and psychological drives rather than an "addiction" (Luik, 1996; Parascandola, 2011).

The growing characterisation of smoking as a manifestation of nicotine addiction was connected with the development of research on the pharmacology and biology of smoking in the 1980s (Parascandola, 2011). Revelations in the mid 1990s about the tobacco industry's clandestine manipulation of their products' nicotine levels in order to maintain their addictiveness reinforced the status of nicotine as a tool of the "dark forces" and an enemy of public health (Parascandola, 
2011). However, the collapse of the distinction between dependence and addiction in the tobacco field is also connected with broader shifts in diagnostic instruments and practices, encapsulated in the decision to remove reference to "addiction" from the revised third edition of the American Psychiatric Association's Diagnostic and Statistical Manual (DSM-IIIR), published in 1987. Instead, "dependence" became the preferred catchall label because of concerns about the pejorative implications of the former term (O'Brien, Volkow \& Li, 2006). Importantly, part of the logic of favouring the term "dependence" over "addiction" was that "this was a more neutral term that could easily apply to all drugs, including alcohol and nicotine" (O'Brien, Volkow \& Li, 2006, p. 764, emphasis ours).

Yet, although tobacco dependence is recognised as a specific disorder in the current editions of the DSM-IV TR and the WHO's classification of diseases (ICD-10), smokers are unlikely to conform to many of the generic criteria listed for substance dependence. These criteria were developed from research and observations regarding alcohol and opiate use and there is a consequent emphasis on disordered behaviour and social harms, such as failure to fulfil role responsibilities (APA, 2000). When a dependence criterion from the DSM such as "a great deal of time is spent in activities necessary to obtain the substance" is illustrated with the example of chain smoking, the distinctiveness of smoking is highlighted rather than undermined, for chain smoking is likely to be combined with other activities, including work and study, rather than taking up time on its own. Therefore, it is not surprising that the "DSM assessment of tobacco dependence has languished" (Hughes et al., 2010, p. 894).

The uneasy fit between tobacco use and contemporary notions of dependence and addiction may be one of the reasons why nicotine is understood to be both the cause of tobacco 'dependence' and simultaneously the key to treating it. Thus, mainstream approaches to smoking cessation tend to focus primarily on breaking the physical dependence to nicotine through pharmacotherapies such as NRT and bupropion (a nicotinic acetylcholine receptor antagonist), rather than treating the psychological and social aspects of the addiction. Here, tobacco poses a contrast to alcohol and illicit drugs, where successful recovery is generally believed to require extensive work on the self and the establishment of a new identity, new relationships and a new lifestyle, even if pharmacological treatments (e.g. methadone maintenance therapy for heroin addiction) are used.

\section{Nicotine as remedy}

The idea of using nicotine to reduce cigarette cravings was evident from at least the 1940s, as Johnston's (1942) work on the effects of hypodermic nicotine delivery attests. However, it was not until the late 1960s that the first commercial nicotine replacement therapy (NRT) products were developed. According to the website of Nicorette, Nicorette gum was initially developed by Swedish scientists in 1967 in order to overcome challenges experienced by the Swedish Royal Navy in the face of new smoking bans on ships and the need to pacify "short-tempered crews" (Johnson \& Johnson Ltd, 2010). Launched commercially in Switzerland in 1978, the original gum was later followed by transdermal patches, nasal sprays, inhalers and microtabs (Johnson \& Johnson Ltd, 2010). Although Nicorette products continue to dominate the market, in recent years they have been joined by a variety of other NRT brands produced by rival pharmaceutical companies, including: Nicabate, Nicotrol, Habitrol, Nicoderm and QuitX. 
Despite the revaluation of nicotine as a therapeutic agent for those addicted to cigarettes, it nevertheless raised fears that a new form of iatrogenic substance abuse would emerge. Thus, concerns about the "abuse potential" of NRT products have been evident since their launch. When Nicorettes were first introduced in the US in 1984, the FDA mandated that they were only to be available on prescription, which was also the case for the nicotine patches introduced between 1991-1992. By limiting access in this way, the goal was to minimise the potential for "abuse" of these products amongst certain populations, especially teenagers and non-smoking adults, and to ensure that smokers did not engage in "improper use" (i.e. use beyond the recommended period) (Shiffman et al. 1997). In 1996 the FDA approved the switch of three NRT products (Nicorette gum, Nicoderm and Nicotrol patches) from prescription-only to overthe-counter availability, although they were restricted for sale to those aged 18 or older (Shiffman 1997).

This shift in the status of NRT was largely due to two interrelated factors. As Benson (2010) notes, the FDA approval of such products for over-the-counter sale signalled the growing medicalisation of nicotine dependence, which was framed as a chronic condition equivalent to high blood pressure, high cholesterol, diabetes, and major depression. It was also connected with the rise of evidence-based medicine (EBM) in the 1990s, and the stamp of approval EBM provided to NRT as an effective (and cost effective) treatment for tobacco dependence (Lancaster et al. 2000). The hegemony of EBM has seen a variety of influential public health organisations (e.g. US Department of Health \& Human Services, National Institute for Health and Clinical Excellence, WHO, etc.) endorse the use of NRT products as an effective aid for treating tobacco dependence (see Raw et al., 2002). The extent of the public health embrace of NRT is evident in the WHO's decision in 2009 to add two forms of NRT (gum and patches) to its list of essential medicines (WHO, 2009).

However, the category of remedial nicotine products in public health discourse is tightly restricted. Although studies comparing the health risks of smoking vs. smokeless tobacco ${ }^{3}$ consumption are lacking, available evidence indicates that the latter is significantly less harmful than smoking (Royal College of Physicians, 2007). One panel of experts estimated a 90\% reduction in relative risk of low-nitrosamine smokeless tobacco use in comparison with smoking (Levy et al., 2004). However, these products are discursively separated from medicinal nicotine, and the majority of mainstream public health and tobacco control organisations remain opposed to their potential as harm reduction products (McNeill, 2004; Hall, 2005; Sweanor, Alcabes \& Drucker, 2007). For example, the World Health Organization makes no distinction between cigarettes and other forms of tobacco in the production of "tobacco-related disease"4 (see WHO, 2011). Similarly, the FDA's position is that: "To date, no tobacco products have been scientifically proven to reduce risk of tobacco-related disease, improve safety or cause less harm than other tobacco products" (FDA, 2011). Thus, any tobacco company claiming that smokeless tobacco is a "less toxic" product than cigarettes is at risk of an accusation of health fraud by the FDA.

The antagonism towards smokeless tobacco is purportedly due to the lack of independent testing of these products to verify their efficacy, safety and harm reduction potential. It is also connected with the fact that they are produced by the tobacco industry and underlying fears that 
an expanded view of tobacco harm reduction "will help sustain existing tobacco markets and facilitate new ones" (Benson, 2010, p. 52).

E-cigarettes have the potential to challenge the binary model of nicotine in which the drug is either purely medicinal or irretrievably linked to the promotion of tobacco consumption. Ecigarettes are not produced by the tobacco industry, nor the pharmaceutical industry; moreover, unlike smokeless tobacco products, they are being widely marketed as smoking cessation devices. Finally, although they look much like a cigarette, they contain no tobacco. Yet, despite these differences (or perhaps because of them), the reception of e-cigarettes has been far more hostile than the response to smokeless tobacco products.

\section{E-cigarettes as a dangerous, untested product}

Amongst public health organisations, the most commonly stated concerns about e-cigarettes relate to their safety. For example, the WHO (2008) and the FDA (2011) have decried the lack of "safety and efficacy" of e-cigarettes in contrast to "proven" alternatives such as NRT. There has been a particular focus on the toxicity of the liquid nicotine solution used in e-cigarettes and the potential for users to spill the liquid on their skin, or for children to accidentally swallow it and overdose (e.g. Queensland Health, 2011). The fact that most e-cigarettes come from China features prominently in the discourse on e-cigarette safety (e.g. Ang, 2009) and appears to play into larger cultural tropes about Western markets being flooded with Chinese products (here, Chinese becomes synonymous with faulty, deficient and dangerous).

Concerns about the potential safety risk e-cigarettes pose to 'innocent children' extend beyond the apparent toxicity of nicotine solution and are tied up with the potential for abuse and youth uptake. For example, a recent commentary in the prominent journal Tobacco Control (Noel et al., 2011) states, "research on product design, toxicant exposure, abuse liability including dual use with tobacco products, youth initiation, and influence on cessation efforts is needed" (p. 81, emphasis ours). Such fears echo the concerns initially raised by the FDA about NRT products (the same products the FDA now declares as safe), evoking anxieties about "gateway drugs" (e.g. Lazar, 2011): substances which may have relatively mild effects in themselves but which encourage users, especially the young, to experiment with 'harder' drugs.

However, while e-cigarettes have not been 'proven' harmless, harm reduction advocates point out that they are indisputably less harmful than smoking (Keller, 2010; McQueen et al., 2011). Moreover, this reluctance to endorse the harm reduction potential of e-cigarettes because they are not entirely free of health risks stands in contrast to the promotion of substitution therapy for opiate addiction. Despite the fact that methadone is a potent opiate with potentially fatal side effects (especially in interaction with other medications) it is regarded as a safe and effective therapy when dispensed to drug dependent patients under medical supervision.

Thus, the response to e-cigarettes in public health and tobacco control circles cannot be explained merely by the potentially unsafe nature of these products. As Siegel (2010) points out, the tone of some mainstream tobacco control commentaries suggests that e-cigarettes have been damned without trial. Moreover, it is not clear that further research into e-cigarettes will substantially alter current opinion. This is because their dangers stem not merely from the constituents of the products themselves, but the ideological challenge they pose to the binary 
categorisation of nicotine into not only remedial and harmful forms, but morally 'good' and 'bad' ones.

\section{'Good' nicotine does not signify smoking}

One of the most obvious differences between e-cigarettes and NRT is that a person vaping an ecigarette looks much the same as a person smoking a cigarette in so far as all of the visible signifiers of the cigarette are present: from its thin, white cylindrical shape and 'lighted' tip, to the plumes of 'smoke' that emanate from the vaper's mouth. In contrast, the most popular forms of NRT (and the two on the WHO's list of essential medicines) are discreet: the gum looks like an innocuous product and the patches are skin-coloured and designed to be hidden under clothing.

The most notable exception is the nicotine inhaler: an NRT product developed based the "handto-mouth ritual" that smoking entails (Johnson \& Johnson, 2011). It is probably not a coincidence that inhalers were released in 1996, well after NRT had gained legitimacy as a medicine. However, although the nicotine inhaler resembles a cigarette in a very general way (it is white and cylindrical), it could hardly be mistaken for one, and numerous Facebook groups decry its distinctly tampon-like appearance. In developing NRT products, the pharmaceutical industry must engage in a delicate balancing act: these products must be similar enough to cigarettes to be effective as a replacement therapy but different enough to retain legitimacy as a 'medicine'. According to Jack Henningfield, "if any system comes too close to being considered a cigarette it risks control in the US by the Drug Enforcement Administration. Nasal NRT came within a hair's breath of this fate" (cited in Chapman, 2007, p. 110).

E-cigarettes, on the other hand, closely mimic cigarettes, maintaining perhaps the most powerful semiotic referent of the cigarette: its smoke. Although the vapour exhaled by the vaper has none of the effects of secondhand smoke, it is visually similar. Thus, the e-cigarette is disturbing to many tobacco control campaigners and researchers because of its mimetic relationship to the traditional cigarette. While it does not contain tobacco or involve a process of combustion, it is an unmistakable signifier of smoking and therefore invokes both the memory of public smoking culture and its possible resurgence.

This is problematic from the perspective of mainstream tobacco control because of the centrality of tobacco 'denormalisation' to its contemporary strategies. Reducing the visibility of smoking is therefore a key component of contemporary tobacco control, and is central to the logic of smokefree legislation and restrictions on how tobacco products may be marketed and sold (see Bell et al., 2010a, 2010b). That e-cigarettes are perceived to undermine this intent becomes evident in statements such as: "Fake smokes [e-cigarettes], many of which look almost indistinguishable from real cigarettes, keep smoking in the public eye and help normalize the act of lighting up" (Chen, 2011). The strong reaction against these devices suggests that the culture of cigarettes and smoking (in the broad sense) is viewed as an inseparable and inherent element of the harms of tobacco consumption. Therefore, any device that enables smoking-like practices is a public health threat. 


\section{'Good' nicotine is medicinal, not recreational}

Also central to the differing legitimacy accorded to NRT and e-cigarettes is the specified purpose of these products. Theoretically at least, the use of NRT is temporary: it is a 'medicine' that 'cures' smokers of their nicotine addiction. NRT products are thus marketed as smoking cessation aids, not maintenance therapies. For example, users of Nicorette products (gums, inhalers and patches) are advised to undertake a tapering 16-week program, from beginning their use of the product, "until you can do without it" (Johnson \& Johnson, 2011). Here, NRT is ideologically situated in opposition to other forms of nicotine delivery (e.g. e-cigarettes and smokeless tobacco products), which are intended to be used as potentially permanent replacements for or supplements to cigarettes.

NRT only retains its legitimacy as long as it treats nicotine addiction, rather than perpetuating it. However, in reality this division is difficult to maintain. As previously noted, the concern about the abuse potential of NRT has been evident right from when it was first introduced on the market. Indeed, a number of people have written confessional pieces about replacing their cigarette addiction with a Nicorette addiction (e.g. Joseph, 2010). There are also several Facebook groups devoted to this topic, including "Nicorette Addicts" (containing 19 members) and "I'm addicted to Nicorette (but at least I quit smoking)", with 82 members. Websites providing patient reviews of Nicorette also report substitute addiction as a relatively common side effect (Martin, 2010; Askapatient.com, 2011).

Blurring the lines further is the fact that smokers are clearly turning to e-cigarettes as a smoking cessation tool. Although the FDA has mandated that e-cigarettes sold in the USA cannot be marketed as therapeutic devices, many manufacturers make general claims about the health and aesthetic benefits of using their product as a substitute for smoking (Trtchounian \& Talbot, 2011). Moreover, there is also some evidence to suggest that e-cigarettes $d o$ reduce the desire to smoke and help smokers to quit smoking (Bullen et al., 2010; Heavner et al., 2010; Siegel et al., 2011; McQueen et al., 2011) and they have been reported to be used in much the same way as NRT (Etter \& Bullen, 2011). For example, in a small interview-based study of vapers, McQueen et al. (2011) found that most e-cigarette users were heavy smokers (or formerly heavy smokers) who had tried to quit with traditional NRT. These users endorsed e-cigarettes as "life-saving" and their immediate benefits were seen to outweigh the potential for currently unknown longterm harms.

Thus, 'good' nicotine has an unstable identity, whereby the therapeutic project to rid the smoker of his or her addiction is undermined by the abuse potential of the drug. Like other psychoactive substances that are simultaneously both 'useful medications' and 'abusable drugs', "maintaining the line between the proper use and harmful misuse of psychoactive substances requires careful discursive and practical management" (Keane, 2008, p. 5, see also Bell \& Salmon, 2009). Such boundary management is evident in the ideological distinction made between "smoking cessation" via NRT and "substituting for smoking" via e-cigarettes (Phillips, 2011).

In the case of Methadone (as a treatment for opiate dependence) and amphetamine-like stimulants (as treatments for ADHD), the clinical context of diagnosis and prescription, plus an enmeshment in the institutional structures of medicine and education, establishes their status as beneficial medications rather than dangerous drugs (Keane, 2008). Crucially, their consumption 
is separated from the discourses of recreation and pleasure associated with drug abuse. Methadone is not prescribed to replace the rewards or pleasures of illicit drug use but to produce stasis and prevent withdrawal (valentine \& Fraser, 2008, p. 414). Indeed, official support for methadone as a treatment is based on its credentials as a pleasure-blocking substance. The US Office of Drug Control policy's fact sheet on methadone states that "Methadone...blocks the high from heroin but it does not provide the euphoric rush" (cited in Keane 2008, p. 406-7).

Without the discursive and practical benefits of medicalisation, e-cigarettes remain located as products consumed for pleasure. The rapid rise of a vaping subculture, where e-cigarette enthusiasts come together at regional festivals ("Vapefests") and share nicotine solution recipes and product reviews through a monthly magazine, entrench its status as a pleasurable, recreational drug. However, the hobbyist dimension of e-cigarettes sits alongside an explicit awareness of its health benefits and harm reduction potential (Phillips, 2011). For example, a recent issue of Vaper Monthly juxtaposes advertisements for Pink Spot Vapors, a producer of nicotine solutions whose slogan is "Happy vaping! This juice will hit the spot", with an interview with 'TrueLove', a member of the vaping community who describes how e-cigarettes saved his life. In his words, "I was pretty much dying. After 22 years of smoking I was at my last hope. My doctor pretty much said, 'if you don't quit, you're dead'” (Vaper Monthly, 2011).

Thus, e-cigarettes are threatening because they suggest that the pleasures of nicotine can be accessed without the harms and that a culture of smoking/vaping may be able to co-exist with the requirements of public health. This poses a challenge to contemporary conceptions of public health, which has long manifested a suspicion towards pleasure, especially the carnal pleasure associated with drugs (Coveney \& Bunton, 2003; Bunton \& Coveney, 2011). As Coveney and Bunton (2003) note, in mainstream public health models, health and pleasure are generally defined in opposition, with "injunctions towards healthy behaviours concerned with restricting or overcoming our seemingly 'natural' inclination towards certain pleasures" (p. 163).

\section{Conclusion}

By delivering nicotine in way that resembles the visual spectacle and bodily pleasures of smoking, but without the harms of combustible tobacco, e-cigarettes highlight the complex status of nicotine as both poison and remedy in contemporary public health and tobacco control. The introduction of NRT and its visibility in smoking cessation campaigns established nicotine as a remedial substance, and the non-cigarette-like nature of NRT products has enabled them to be distanced from the spectre of pleasurable nicotine use and its addictive potential.

The bad nicotine/good nicotine distinction is based in part on the attribution of addictiveness and its connotations of disorder and disease. On one hand, nicotine is understood within tobacco control as the addictive substance that drives smokers to continue smoking despite its obvious dangers, its increasing stigmatisation and a genuine desire to quit. The drug has taken on a central role as an agent of the smoking epidemic and thus has connotations of toxicity and deadliness, in addition to the generic negative associations of addictive substances. On the other hand, by promoting forms of medicalised nicotine that are advertised on television and available over the counter, the success of NRT has provided a new role for nicotine. However, its legitimacy is fragile and relies on careful discursive management. 
E-cigarettes expose the artificial boundaries placed upon 'good' and 'bad' nicotine and their hostile reception needs to be understood in relation to this. They also challenge the equation between addiction and harm, suggesting the potential for nicotine addiction without the harms of smoking and many of its pleasures. By unabashedly foregrounding pleasure, these products contest its construction as the 'enemy' of public health and make explicit the moral underpinnings of contemporary notions of health, disease and addiction.

\section{Notes}

${ }^{1}$ Using heat, the implement vaporises a propylene glycol or glycerin-based liquid solution containing nicotine and/or added flavours into an inhaled mist that bears the physical appearance and sensation of inhaled tobacco smoke (Wikipedia, 2011).

${ }^{2}$ Although the listserv has a harm reduction agenda, it covers both positive and negative depictions of ecigarettes.

3 'Smokeless tobacco' actually refers to a wide range of very different products, including chewing tobacco, dipping tobacco, snuff, snus, tobacco gum, etc. Although all products are substantially less toxic than cigarette smoking, the harms associated with them differ. For example, while chewing tobacco does slightly increase the risk of oral cancer (although the relative risks are exponentially lower than the risks associated with smoking), products such as Swedish snus appear to carry little if no health risks (Sweanor, Alcabes \& Drucker, 2007).

${ }^{4}$ Here, the WHO seems to adhere to standards of evidence far beyond those deemed acceptable for other public health issues such as obesity and alcohol use (see Bell, McNaughton \& Salmon, 2011), suggesting a degree of 'cherry-picking' regarding evidence and what constitutes an acceptable 'base' (we are indebted to one of the anonymous manuscript reviewers for this insight).

\section{References}

Ang, A. (2009). Chinese e-cigarettes gain ground amid safety concerns. Mail \& Guardian Online. http://mg.co.za/article/2009-02-28-chinese-ecigarettes-gain-ground-amid-safety-concerns. Accessed 13.09.11.

APA (2000). Diagnostic and statistical manual of mental disorders, fourth edition, text revision (DSM$I V$-TR). Arlington, VA: American Psychiatric Association.

Askapatient.com (2011). Drug ratings for http://www.askapatient.com/viewrating.asp?drug=18612\&name=NICORETTE. $\quad$ Accessed 13.09.11.

Bell, K., McCullough, L., Salmon, A., \& Bell, J. (2010a). 'Every space is claimed': Smokers' experiences of tobacco denormalisation. Sociology of Health \& Illness, 32(6), 1-16.

Bell, K., McNaughton, D., \& Salmon, A. (2011). Alcohol, tobacco and obesity: Morality, mortality and the new public health. London: Routledge.

Bell, K., \& Salmon, A. (2009). Pain, physical dependence, and pseudoaddiction: Redefining addiction for 'nice' people? International Journal of Drug Policy, 20, 170-178.

Bell, K., Salmon, A., Bowers, M., Bell, J., \& McCullough, L. (2010b). Smoking, stigma and tobacco 'denormalization': Further reflections on the use of stigma as a public health tool. Social Science \& Medicine, 70, 795-799.

Benson, P. (2010). Safe cigarettes. Dialectical Anthropology, 34, 49-56.

Berridge, V. (1998). Science and policy: the case of postwar British smoking policy. In S. Lock, L.A. Reynolds \& E.M. Tansey (Eds), Ashes to ashes: the history of smoking and health (pp. 143-162). Amsterdam: Rodopi.

Berridge, V. (1999). Passive smoking and its prehistory in Britain: Policy speaks to science? Social Science \& Medicine, 49, 1183-1195. 
Boen, H. (2011). E-cigarette distributors fired up over recent FDA announcement: Products to be regulated like tobacco. Reporter News. http://www.reporternews.com/news/2011/apr/27/ecigarette-distributors-fired-up-over-recent/. Accessed 13.09.11.

Bullen, C., McRobbie, H., Thornley, S., Glover, M., Lin, R., \& Laugesen, M. (2010). Effect of an electronic nicotine delivery device (e cigarette) on desire to smoke and withdrawal, user preferences and nicotine delivery: randomised cross-over trial. Tobacco Control, 19(2), 98-103.

Bunton, R., \& Coveney, J. (2011). Drugs' pleasures. Critical Public Health, 21(1), 9-23.

Chapman, S. (2007). Public health advocacy and tobacco control: Making smoking history. Oxford, UK: Blackwell.

Chen, A. (2011). If e-cigarettes aren't harmful, then prove it. The News Tribune. http:/www.thenewstribune.com/2011/05/13/1663467/if-e-cigarettes-arentharmful.html\#ixzz1U6Za2AKN. Accessed 15.09.11.

Coveney, J., \& Bunton, R. (2003). In pursuit of the study of pleasure: Implications for health research and practice. Health (London), 7, 161-179.

Etter, J-F., \& Bullen, C. (2011). Electronic cigarettes: users' profile, utilization, satisfaction and perceived efficacy. Addiction, DOI: 10.1111/j.1360-0443.2011.03505.x

FDA (2011). Health Fraud. US Food \& Drug Administration. http://www.fda.gov/TobaccoProducts/ResourcesforYou/ucm255658.htm. Accessed 14.09.11.

Gray, N., \& Boyle, P. (2003). The future of the nicotine addiction market, The Lancet, 362, 845-6.

Hall, W.D. (2005). The prospects for harm reduction. International Journal of Drug Policy, 16, 139-142.

Health Canada (2009). Health Canada advises Canadians not to use e-cigarettes. http://www.hcsc.gc.ca/ahc-asc/media/advisories-avis/2009/2009 53-eng.php. Accessed 13.09.11.

Heavner, K., Dunworth, J., Bergen, P., Nissen ,C., \& Phillips, C.V. (2010). Electronic cigarettes (ecigarettes) as potential tobacco harm reduction products: Results of an online survey of e-cigarette users. In C.V. Phillips \& P. Bergen (Eds), Tobacco Harm Reduction 2010 Yearbook (pp. 257-270). Canada: TobaccoHarmReduction.org.

Hughes, J.R., Baker, T., Breslau, N., Covey, L., \& Shiffman, S. (2011). Applicability of DSM criteria to nicotine dependence. Addiction, 106(5), 894-895.

Irish Central (2011). Electronic cigarettes taken off shelves in Ireland. http://www.irishcentral.com/story/roots/emeraldextracts/electronic-cigarettes-taken-off-shelves-inireland-126572683.html. Accessed 13.09.11.

Johnson \& Johnson (2010). Nicorette: smoking cessation pioneers. Nicorette. http://www.nicorette.in/nicorette/history. Accessed 15.09.11.

Johnson \& Johnson (2011). Giving up smoking with the Nicorette inhaler. Nicorette. http://www.nicorette.ca/stopsmoking/products/inhaler.aspx?gclid=CKCUzdWKoqsCFYYZQgod7lkEiQ. Accessed 16.09.11.

Johnston, L.M. (1942). Tobacco smoking and nicotine. The Lancet, December 19, 742.

Joseph, C. (2010). I gave up smoking ten years ago - but I'm still addicted to nicotine. Mail Online. http://www.dailymail.co.uk/health/article-1245532/I-gave-smoking-years-ago--Im-addictednicotine.html. Accessed 15.09.11.

Keane, H. (2002). Smoking, addiction, and the making of time. In J.F. Brodie \& M. Redfield (Eds), High Anxieties: Cultural Studies in Addiction (pp. 119-133). Berkeley: University of California Press.

Keane, H. (2008). Pleasure and discipline in the uses of Ritalin. International Journal of Drug Policy, 19(5): 401-9.

Keller, E.D. (2010). No compelling evidence of harm or danger. Response to 'Electronic cigarettes: Miracle or menace?' British Medical Journal, 340:c311 doi: 10.1136/bmj.c311.

Lancaster, T., Stead, L., Silagy, C., \& Sowden, A. (2000). Effectiveness of interventions to help people stop smoking: Findings from the Cochrane Library. British Medical Journal, 321, 355-8.

Lazar, K. (2011). Boston wants new limits on e-cigarettes. Boston.com. http://articles.boston.com/201109-09/lifestyle/30136134 1 e-cigarettes-regular-cigarettes-smoker-inhales. Accessed 15.09.11. 
Levy, D.T., Mumford, E.A., Cummings, K.M., Gilpin, E.A., Giovino, G., Hyland, A., Sweanor, D., \& Warner, K.E. (2004). The relative risks of low-nitrosamine smokeless tobacco product compared with smoking cigarettes: Estimates of a panel of experts. Cancer Epidemiology, Biomarkers and Prevention, 13(12), 2035-2042.

Luik, J.C. (1996). 'I can't help myself': Addiction as ideology. Human Psychopharmacology, 11, S21S32.

Martin, T. (2010). I'm addicted to nicotine gum - Is that so bad? http://quitsmoking.about.com/od/nrts/f/nicotinegum.htm. Accessed 15.09.11.

McNeill, A. (2004). Harm reduction. British Medical Journal, 328, 885-887.

McQueen, A., Tower, S., \& Sumner, W. (2011). Interviews with 'vapers': Implications for future research with electronic cigarettes. Nicotine \& Tobacco Research, doi: 10.1093/ntr/ntr088.

Noel, J.K., Rees, V.W., \& Connolly, G.N. (2010). Electronic cigarettes: a new 'tobacco' industry? Tobacco Control, $20,81$.

NZ Ministry of Health (2011). Smokefree Environments (Controls and Enforcement) Amendment Bill. http://www.endsmoking.org.nz/MoH\%20on\%20ecigs\%20etc.pdf. Accessed 13.09.11.

O'Brien, C.P., Volkow, N., \& Li, T-K. (2006). What's in a word? Addiction versus dependence in DSMV. American Journal of Psychiatry, 163(5), 764-765.

Parascandola, M. (2011). Tobacco harm reduction and the evolution of nicotine dependence. American Journal of Public Health, 101(4), 632-641.

Phillips, C.V. (2011). Greetings from Vapefest Philadelphia. Tobacco Harm Reduction: Views and Opinions. $\quad$ http://smokles.wordpress.com/2011/03/25/greetings-from-vapefest-philadelphia/. Accessed 13.09.11.

Queensland Health (2011). Media Statement: Regional Queenslanders warned e-cigarettes are poison. http://www.health.qld.gov.au/news/media_releases/qhe_cigs0515.pdf. Accessed 13.09.11.

Raw, M., Anderson, P., Batra, A., Dubois, G., Harrington, P., Hirsch, A., Le Houezec, J., McNeill, A., Milner, D., Poetschke Langer, M., \& Zatonoski, W. (2002). WHO Europe evidence based recommendations on the treatment of tobacco dependence. Tobacco Control, 11, 44-46.

Room, R. (2003). The cultural framing of addiction. Janus Head, 6(2), 221-234.

Royal College of Physicians. (2007). Harm reduction in nicotine addiction: Helping people who can't quit. A Report by the Tobacco Advisory Group of the Royal College of Physicians. London: RCP.

Shiffman, S. Gitchell, J., Pinney, J.M., Burton, S.L., Kemper, K.E., \& Lara, E.A. (1997). Public health benefit of over-the-counter nicotine medications. Tobacco Control, 6(4), 306-310.

Siegel, M. (2010). Article on electronic cigarettes draws conclusion before data are in: Why is the research necessary? The Rest of the Story: Tobacco News Analysis and Commentary. http://tobaccoanalysis.blogspot.com/2010/10/article-on-electronic-cigarettes-draws.html. Accessed 16.09.11.

Siegel, M.B., Tanwar, K.L., \& Wood, K.S. (2011). Electronic cigarettes as a smoking-cessation tool: results from on online survey. American Journal of Preventive Medicine, 40(4), 472-5.

Steinberg, M.B., Schmelzer, A.C., Richardson, D.L., \& Foulds, J. (2008). The case for treating tobacco dependence as a chronic disease, Annals of Internal Medicine, 148, 554-556.

Sullum, J. (1998). For your own good: the anti-smoking crusade and the tyranny of public health. New York: Free Press.

Sullum, J. (2011). E-cigarettes will remain legal but unregulated until the FDA issues new rules. Reason. http://reason.com/blog/2011/05/02/e-cigarettes-will-remain-legal. Accessed 13.09.11.

Sweanor, D., Alcabes, P., \& Drucker, E. (2011). Tobacco harm reduction: How rational public policy could transform a pandemic. International Journal of Drug Policy, 18, 70-74.

Trtchounian, A., \& Talbot, P. (2011). Electronic nicotine delivery systems: is there a need for regulation? Tobacco Control, 20, 47-52.

valentine, K., \& Fraser, S. (2008). Trauma, damage and pleasure: Rethinking problematic drug use. International Journal of Drug Policy, 19(5), 410-416. 
Vaper Monthly (2011). Community spotlight: TrueLove. http://vapermonthly.com/2011/05/03/community-spotlight-truelove/. Accessed 16.09.11.

WHO (2008). Marketers of electronic cigarettes should halt unproved therapy claims. http://www.who.int/mediacentre/news/releases/2008/pr34/en/index.html. Accessed 13.09.11.

WHO (2009). Two forms of nicotine replacement therapy chosen as WHO 'Essential Medicines'. WHO Communications.

http://www.who.int/tobacco/communications/highlights/note nrt therapy/en/index.html. Accessed 15.09.11.

WHO (2011). WHO report on the global tobacco epidemic, 2011: Warning about the dangers of tobacco. Geneva: World Health Organization.

Wikipedia (2011). Electronic cigarette. http://en.wikipedia.org/wiki/E-cigarettes. Accessed 26.09.11 